\title{
Straying From the Beaten Path, and Other Stories About Molecules
}

\author{
Lawrence S. Bartell ${ }^{1}$
}

Received September 10, 2004; accepted October 6, 2004

What determines a person's course in life is to a great extent an accident. Even though my entry into the field of electron diffraction was largely a matter of chance, once in the field, I found it offered an extraordinary opportunity for scientific adventure. The following stories recount some of the serendipitous advances in the field that came from probing molecules by electron waves, as well as references to a few of the interesting personalities who played a role in the field.

KEY WORDS: Electron diffraction; molecular properties; theory of diffraction; advice to beginners.

\section{INTRODUCTION AND EARLY EXPERIENCES}

Electron waves have remarkable properties that not only make them nearly ideal for probing the structures of gas-phase molecules but also make possible the study of atomic and molecular properties not even considered in the early days of their application. The following personal stories will recount some steps along the evolution of the field. I'll leave the task of compiling a complete chronological history to others.

Lawrence O. Brockway was not the first to record electron diffraction patterns of gas-phase molecules in order to determine their structures. Nevertheless, owing to the untimely death of R. Wierl, the brilliant young collaborator of Herman Mark, who had been the first, it fell to Brockway to pioneer and establish the field of gasphase electron diffraction. How this came about was told by Brockway in the book of reminiscences Fifty Years of Electron Diffraction [1]. When he went to Cal Tech as a fresh young graduate student, Brockway had no idea of carrying out research on electron diffraction. Because he had expressed an interest in the structure of matter, however, he was assigned to be a student of Linus Pauling. Brockway recalled "Pauling's first suggestion was that I should embark upon the seas of crystal structure by X-ray diffraction. For some reason still unknown to me the various projects he suggested seemed unattractive

\footnotetext{
${ }^{1}$ Department of Chemistry, University of Michigan, Ann Arbor, Michigan 48109.
}

and I kept refusing. Finally, in desperation, he spoke of an experiment he had seen in the summer of 1930 while he was visiting the laboratories of the I. G. Farben Industrie, carried out by Mark and Wierl... Although there had been no publication describing either the equipment or the method of interpreting the recorded [electron] diffraction patterns, I felt I should agree to try the experiment before Pauling became completely disenchanted with this new graduate student." So began the history of gas-phase electron diffraction (GED) in America and, effectively, the world.

Brockway (Fig. 1) was my mentor when I was a graduate student, not because I had any intention of devoting my career to GED but because the research projects of the other faculty members were distinctly less interesting to me than Brockway's. As a matter of fact, when I was an undergraduate student, I had become captivated by the field of radiochemistry. Surely it was the most exciting field in the whole of science! Then, early in 1944, I had a chance to find out, first hand, what radiochemistry was really like. Glenn Seaborg hired me (and dozens of other young chemists with fresh BS degrees) to work on the Manhattan Project at the University of Chicago [2]. My assigned problem was to test methods of extracting and decontaminating plutonium from slugs of uranium that had been irradiated in a reactor. The process I worked on was actually that which was used to produce plutonium for the Nagasaki bomb. Later, more efficient ways were developed. In any event, getting contaminated every day and doing the repetitive operations of precipitating, 


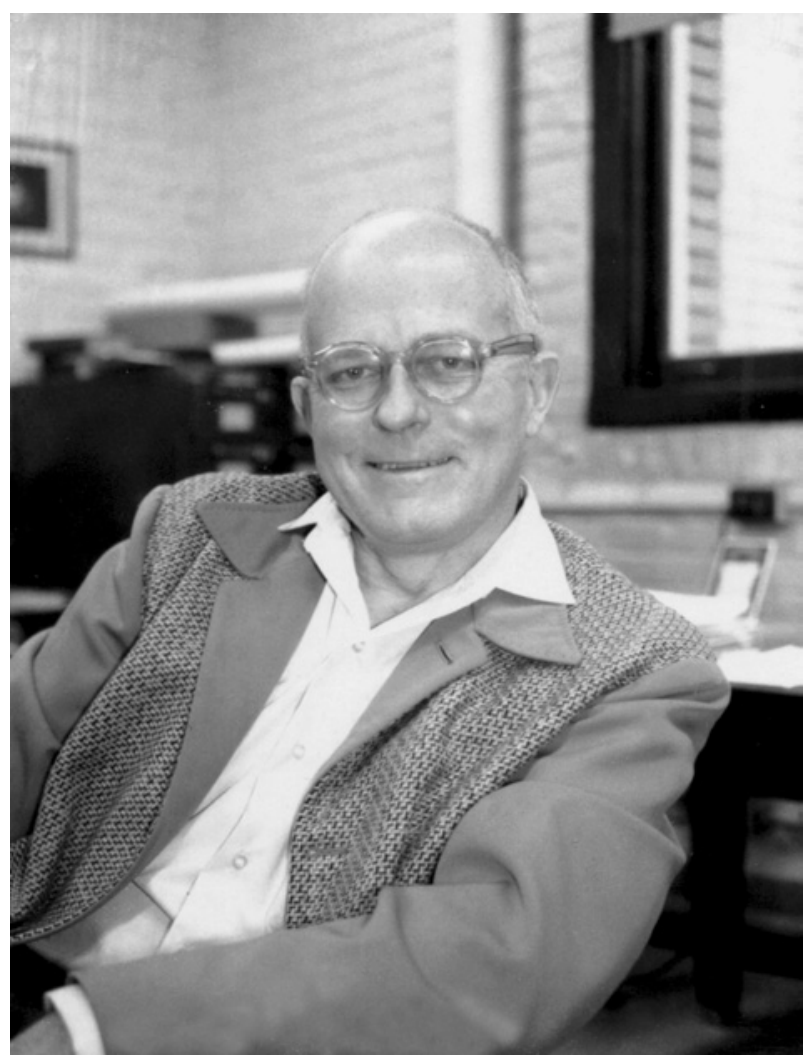

Fig. 1. Lawrence Brockway in 1959. He was a man with diverse interests and a zest for life. As well as being an uncommonly successful scientist, he was an Elder in the Reorganized Latter Day Saints Church and, indeed, is the cleric who married the author to his wife.

centrifuging, filtering, redissolving, pipetting, precipitating, and using Geiger counters to assay samples day after day after day, quickly gave me my fill of radiochemistry. In just 1 year, I'd had more than enough for a lifetime when, almost to my relief, I received a telegram from the President of the United States of America ordering me to report for duty in the armed forces. I chose the navy. When I got out of the navy and embarked on a chemical career as a graduate student, I got as far from radiochemistry as I could, and playing with electron waves did seem a rather interesting way of doing it.

In the last paper he ever wrote, the aforementioned chapter in the book Fifty Years of Electron Diffraction [1], Brockway finished by saying "The developments after the late 1930s are fairly well known. My own recollections of the earliest days are centered around the sense of excitement and fun, and an appreciation of the opportunity to work in a major scientific development while still enrolled as a new graduate student." It would reward the reader to learn what else Brockway wrote about in his brief, essentially obituary, notes (for he died while he was roughing out those notes). But the impression that his notes might give, namely, that a sense of adventure had left the field once it had become established, is misdirected. Many exciting developments remained to be explored. Even before I entered the field, however, the brilliant pioneer of microwave spectroscopy, the acerbic E. Bright Wilson, who had been a laboratory mate of Brockway during their student days at Cal Tech, wrote the obituary of gas-phase electron diffraction. Wilson believed that microwave spectroscopy had usurped the field of gas-phase structural research, leaving the field of electron diffraction far behind. It was certainly true in the early days, that microwave spectroscopy yielded structures of simple molecules which were considerably more accurate than those found by gas-phase electron diffraction. Nevertheless, I was convinced that the notion that GED had become irrelevant was unfounded. It was clear to me, on the one hand, that the diffraction apparatus and means of measuring intensities could be greatly improved. On the other hand, atomic motions in molecules confused the interpretation of microwave spectra more than Wilson appreciated at the time. I was very lucky to have the opportunity to participate in major advances in instrumentation and interpretation that made gas-phase electron diffraction quite competitive with microwave studies. Moreover, as time passed, I could see that the diffraction technique could successfully study subjects its spectroscopic competitor could not handle easily or at all. Cases in point were, of course, molecules with no dipole moment but also certain very unstable molecules, very hot molecules, and laserpumped molecules. Another development of gas-phase electron diffraction that the microwave method could not even begin to tackle was the study of large, gas-phase clusters, that is, large aggregates of molecules. Typically, these clusters contained hundreds to many thousands of molecules. The diffraction patterns of such clusters revealed the manner in which molecules chose to pack, i.e., the thermodynamic phase. Even more interestingly, it turned out that we could also observe clusters to undergo phase changes. That opened up a new field. But I am getting ahead of the story.

\section{EARLY RESEARCH AND ADVICE TO BEGINNERS}

When I meet young diffractionists, they often recognize me as the person who inserted anharmonicity into the equations used to analyze electron diffraction patterns, and as a courtesy remind me of that fact. Although that is true, it is a rather dreary way to be remembered and the story isn't one of the fondest memories of my scientific career. My involvement with that development is easy enough to 
understand. Before my first work, diffraction units were quite primitive, among other things, in allowing the strong undiffracted beam to strike the photographic plate recording the diffraction pattern. This would generate a heavy spray of spurious radiation that also registered on the plate. Moreover, measurements of diffraction intensities were subjective, visual "eyeball" estimates. When I began to build and refine diffraction equipment [3], including the recording and conversion of diffraction patterns to digital form, it became clear that the patterns I was able to obtain had latent within them more accurate information about molecules than the rather crude diffraction theory of the day was able to extract. Therefore, it was absolutely essential to improve the theory. That is why it was necessary, among other things, to introduce effects of anharmonicity of molecular vibrations into the theobry.

Two things stand out in my mind about this period in my research, one good and one a mixed blessing. First, it was a brilliant young undergraduate student in my group, Denis Kohl (Fig. 2), who conceived of the best way to read

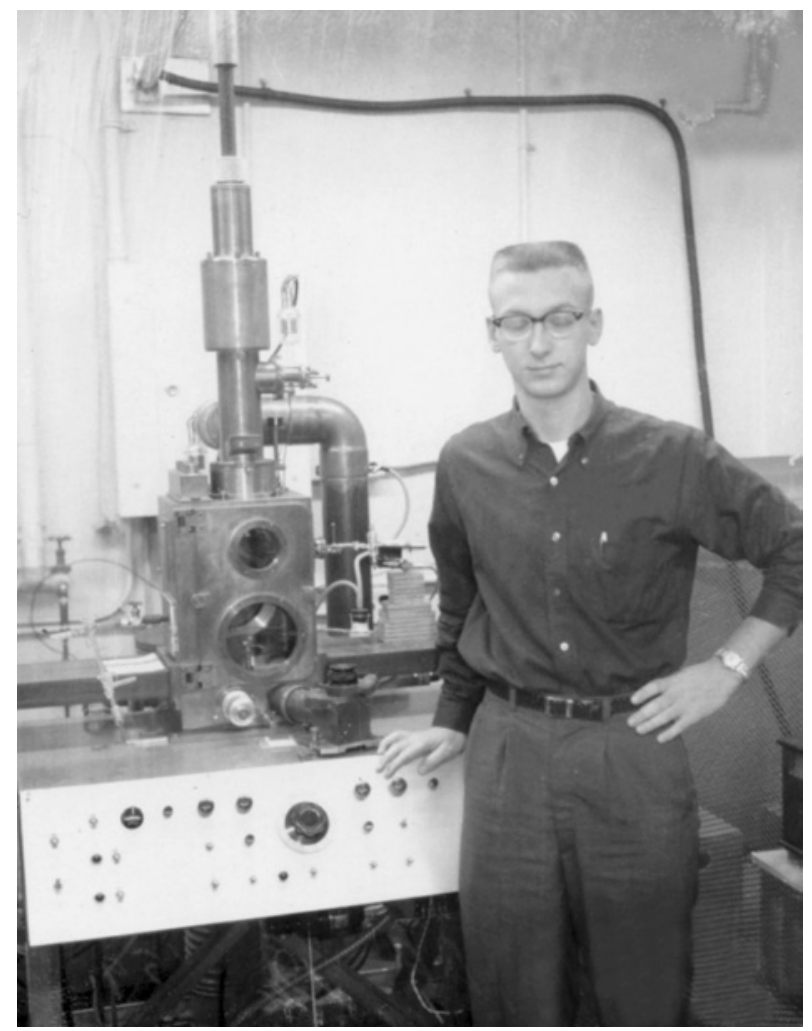

Fig. 2. Denis Kohl when he was an undergraduate student. I had supposed his indefatigable work, even nights before examinations, demonstrated his dedication to science. Later it turned out that funds from his assistantship had a lot to do with the many hours he worked, for it helped him to save for a sports car. Denis is now on the faculty of the University of Texas. and digitize the diffraction intensities. Those who only admit graduate students and postdoctoral scholars into their research groups are missing a good bet. Secondly, and this is a word of advice to young scholars about what can happen in real life. After I submitted my first paper on effects of anharmonicity [4], a rather well-known diffractionist (whose name will not be mentioned here) reviewed the paper and said it was a sterile exercise not worth publishing because diffraction intensities could not be measured accurately enough for my corrections to the standard theory to matter. So, through the editor, I sent the referee a manuscript [5] verifying that we could indeed measure the patterns with the requisite accuracy. What happened next was that the referee told me to rewrite and augment the paper on anharmonicity (which I refused to do) but he told the editor to hold up the paper presenting our new experimental intensities. Because I was merely a beginner in the field, this reviewer of my work succeeded in delaying publication of my second paper for the better part of a year. He did this in order to allow himself to be the first to publish a small idea formulated in my manuscript! He even had the gall to send me a reprint with this idea encircled in red! To me, that idea, while correct, was sufficiently obvious to any thoughtful scientist that it was not only unethical but rather silly for the reviewer to do what he did. Young scholars should not become too discouraged or alienated when they encounter shabby or dishonest behavior from their colleagues (after all, scientists are human beings subject to all of the frailties possessed by others). If young scholars persist, and are right, things will begin to go their way. The same scientist who held up my paper later committed several other scientific improprieties related to my work but, by that time, my reputation had been established and those breaches hardly mattered.

\section{TWO MEMORABLE EXPERIENCES}

I have lived for a long time, and have done too many things related to the topic of this volume, to include here. Since I did enter the field long ago and did work on many different problems, I was recently asked to tell a few stories to an audience about my work in electron diffraction-but it was suggested that I do it in about $6 \mathrm{~min}$ ! Therefore, it was necessary to try to recall what particular experiences in diffraction seemed the most memorable to me, in one way or another.

In ruminating about what might be interesting to narrate in the limited time available, two rather different adventures came to mind. One day before class, two students in my elementary physical chemistry course came up to me and asked "Are you the Bartell in the Guinness Book of 
Records?" I said "I don't know. What does the book say?" They replied that it said something about the "world's most powerful microscope." So I figured I might very well be the Bartell in the Guinness Book. A few years earlier it had dawned on me that, prepared the right way, electron diffraction plates are holograms, and enormously enlarged images of atoms and molecules could be reconstructed by shining laser beams through the plates appropriately. The idea worked. I'll spare readers the details. Anyway, I ran out and bought the book [6] (a paperback copy—no need to invest heavily if my hunch happened to be wrong). I cracked the book open at random and first came across an entry about a quarterback who made the most fumbles in the history of the National Football League. The next entry I noticed was-can you believe it-about a man who ate a bicycle! ATE A BICYCLE!!! He got one, cut it up into tiny pieces, and swallowed them! To its credit, the Guinness Book said it was not going to accept any more entries in THAT category! Anyway, by the time I got to my entry (yes it was there) all feelings of pride of being in the book had evaporated. It was obvious that the easiest way to get into the book is to do something particularly stupid. But the story isn't quite over.

It is apparent that the credentials of the Guinness Book are clearly more impressive to committees than mere publications in the Journal of Chemical Physics or Nature or the Physical Review-for being in the Guinness Book won me more awards than any other single piece of research I ever did-even though the work on electron holography was a very minor part of my research program, done mostly with a couple of undergraduate students. It also led to a personally gratifying correspondence with Denis Gabor, the inventor of holography.

Another memorable project began because of my utter confusion when I was trying to understand diffraction theory and how it was related to the determination of molecular structures. I noticed that the theory for X-ray diffraction differed fundamentally from Debye's theory that we used in electron diffraction. In X-ray crystallography one calculates the amplitude of waves scattered by the electrons in their instantaneous positions, then averages the amplitude over the quantum motions of the electrons, and then squares to get the intensity. On the other hand, electron diffractionists calculate the instantaneous scattered amplitude, square it to get the instantaneous intensity, then average the intensity over the quantum motions of the atoms. Whether first to average, then square or first to square, then average? It was very confusing to me, an experimentalist. I had lunch with Debye shortly after becoming aware of this puzzling question, so I asked him why? He just laughed. He was a genius, the most brilliant person I ever knew, and he didn't suffer fools patiently. He made you work out things by yourself. So, I struggled and struggled and finally understood the results according to the mathematics of quantum theory and began to understand the physical picture, as well. It turned out that both treatments are correct. The X-ray treatment gives the elastic scattering, and Debye's electron diffraction treatment gives the total (elastic plus inelastic) scattering. Debye had understood this as early as 1915 [7] before quantum mechanics had been developed (and, hence, he could only go so far with the idea). Apparently nobody else had spent much time reflecting about it. What was wonderful about having to wrestle with the problem was that I discovered that by playing the elastic vs. the inelastic scattering, it was possible to get a direct experimental measure of electron correlation - to find the distribution of electrons relative to other electrons. Calculating effects of electron correlation via quantum mechanics was an excruciating exercise then. But for this complication, quantum chemistry would have become quantum chemical engineering years ago. What was especially heartwarming was that I made my discovery about electron correlation just before I received an invitation to Debye's 80th birthday celebration in 1964. Cornell University put on a gala, but informal, birthday symposium, and I got to tell a lecture hall filled with scientists more distinguished than I was what I had just found-what was at issue, how it worked, and what you could do with it. And Debye was there. So was E. Bright Wilson, who remarked how interesting it was that electron diffraction could reveal such information! A welcome admission from one who had written the obituary of the field decades before. Moreover, publishing this work with my brilliant student Bob Gavin started programs of computational physics and computational chemistry in five different countries. So my initial utter confusion, followed by the recognition of what Debye had already understood years before, and the demonstration of what could be done with the idea, led to what was probably my single most influential paper [8].

\section{SOMETIMES A LACK OF EXPERIENCE CAN BE AN ASSET}

The foregoing exhausted my 6 min but hardly exhausts recollections of other fond memories-and neither are the following stories anything like a complete history. Another significant advance in the theory of electron diffraction was made because of my limited mastery of mathematics, although this statement may seem counterintuitive. It was finally realized a half-century ago that the simple kinematic theory (Born approximation) upon which the standard equations of electron diffraction were 
based, was inadequate. This recognition came after an electron diffraction study of $\mathrm{UF}_{6}$ based on the Born approximation had indicated that the molecule possessed an extremely distorted structure [9]. Jake Bigleisen, a spectroscopist, however, had already shown conclusively that the molecule was a regular octahedron [10]. Verner Schomaker realized the trouble probably lay in the fact that the Born approximation broke down when electrons were scattered by a very heavy nucleus. Such a failure might well substantially change the diffraction pattern from that calculated by the Born Approximation. Therefore Schomaker contacted the theoretical physicist Roy Glauber and, together, they worked out a theoretical expression which accounted quite well for the observed pattern of the uranium compound [11]. Diffractionists continued to use the Schomaker-Glauber theory when working with molecules containing heavy atoms. Small but significant deviations from theory remained, however, which were simply swept under the rug. Nevertheless, when my excellent student Jean Jacob studied $\mathrm{ReF}_{6}$ and $\mathrm{ReF}_{7}$, her carefully measured diffraction patterns revealed discrepancies too large to ignore [12]. I had great faith in Jean's intensities and was determined to get to the bottom of the problem. I eventually realized that Schomaker-Glauber theory correctly handled the intra-atomic dynamic scattering but left out the interatomic, intramolecular dynamic scattering. Simply put, a heavy atom casts a sort of shadow on downstream atoms, an effect not properly accounted for by the then existing theory. To be sure, the solution to the problem of electron scattering was well understood by theorists, in principle. Of course, quantum mechanics contained the answer. But to calculate the scattering pattern of an arbitrary molecule, and average it over the random orientations possessed by gas-phase molecules, was far from trivial. Skilled mathematicians in Russia had devised an infinite series of an infinite series but their expressions were far too cumbersome to use in structure determinations. The same trouble was characteristic of expressions devised by other theorists. So I hammered away at the problem, even working on it when I traveled, and introduced various simple models to make more intuitive the essence of what was going on. In doing so, trying simple stratagems to facilitate the evaluation of interference patterns resulting from triplets of atoms, I discovered a "magic" transformation that enormously simplified the problem. My very bright student Tuck Wong cleaned up my informal mathematics and found that an application of the magic transformation accounted very well for Jean's intensities [13,14]. Much more experienced mathematicians had devised formal solutions (keeping them from bothering to explore the possibility of a transformation such as the one I had found) but their solutions had never been shown to account for the anomalous features experimentalists saw and were too complex for standard use in molecular structure determinations.

\section{RECREATIONAL INTERLUDES}

Members of my research group worked very hard at improving methods and learning what electron diffraction could tell us about molecules. But recreation did keep our minds from stagnating. One of the most memorable recreational adventures occurred in 1969 when Americans first reached the moon. My group took off several days enjoying picnics and various water sports in between watching spellbinding TV interludes that covered the moon walks. Examples of other recreational activities are illustrated in Figs. 3 and 4 showing Jean Jacob sailing, and her mentor piloting his strange ultralight aircraft.

\section{OUR MOLECULES SUGGEST FLAWS IN ACCEPTED THEORIES OF STRUCTURE}

So far, all of the stories have dealt with methods or with approaches to the practical acquisition of molecular structures and not with the actual results of structure determinations. That is not to imply that structures were not a crucial part of our research. Structures and what they told us were our bread and butter for years. I did not begin to investigate molecular structures, however, until I was a postdoctoral fellow because my $\mathrm{PhD}$ research had been the development of apparatus [3] and the determination of the distribution of electrons in the argon atom [15]. Here it might be mentioned that my thesis, whose main subjects were as described above, was written one hot summer in a local tavern. The beverage served there was refreshing but, more importantly, in sufficient quantities, had the felicitous effect of overcoming my inhibitions about writing. Another thing making the writing less of a hated chore, was that after awhile I began to be joined in the tavern by an attractive woman I had recently met. She was a secretary in the university who ultimately typed my thesis, gratis, and soon became my wife (Fig. 5).

By an accident of fate, I had been rather spoiled by my first structure study. My first molecule was $\mathrm{CF}_{3} \mathrm{Cl}$ [5]. Having $\mathrm{C}_{3 \mathrm{v}}$ symmetry, it possessed only four distinct internuclear distances. Because all four peaks in the experimental radial distribution curve were beautifully separated, it took no cleverness at all to determine the structure. Such simplicity was rarely encountered later.

The first structure studies that did lead to new ideas about bonding and molecular geometry came only after I joined the faculty of Iowa State College of Agriculture 


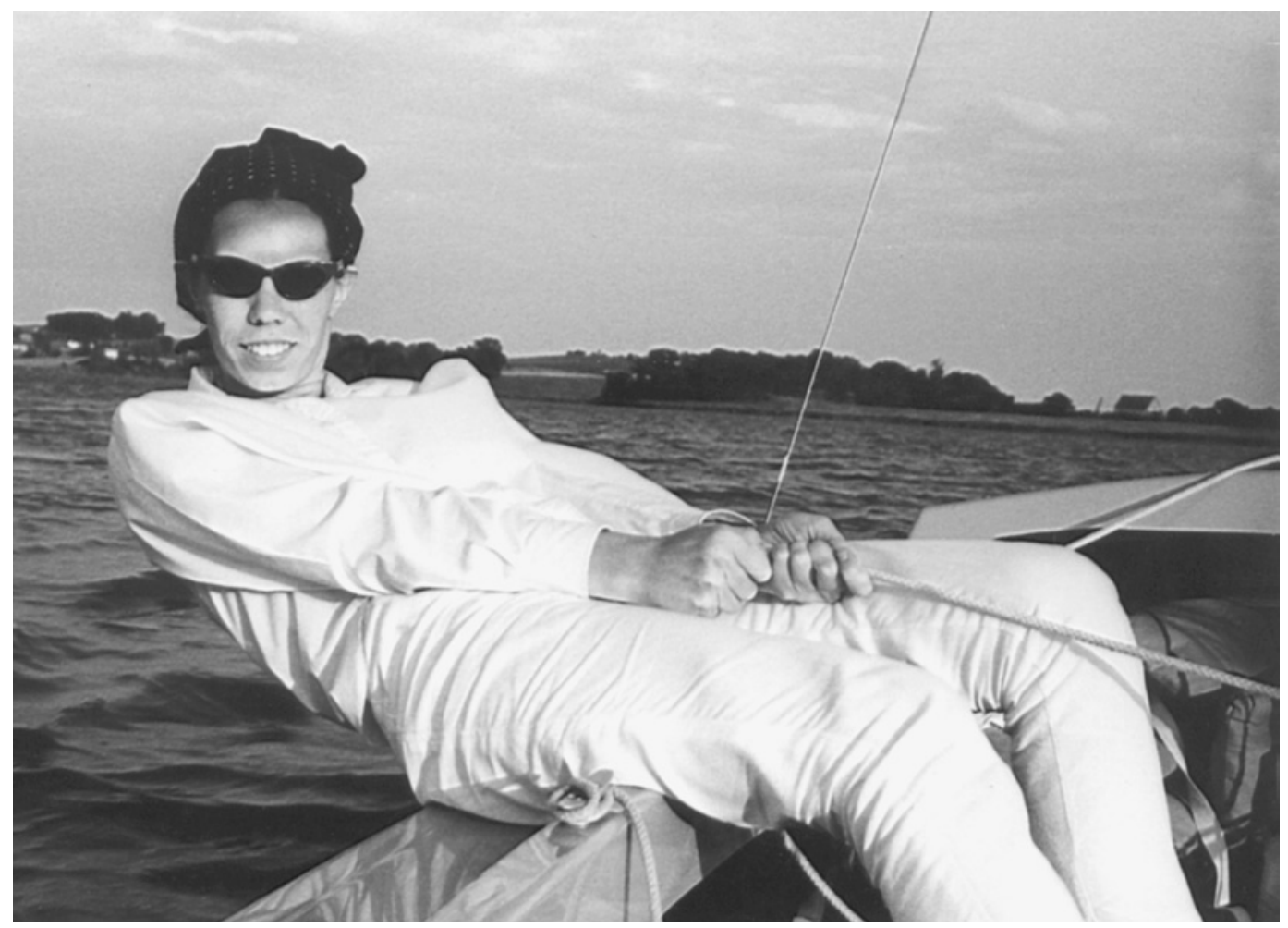

Fig. 3. Jean Jacob at the sheet of a sailboat. After retiring from a faculty position at the University of Toledo she has rejoined the author's group where she far outshines him in her prowess with a computer.

and the Mechanic Arts (later to become known as Iowa State University). However, when I was a new faculty member at Iowa State, I didn't have the resources to continue my research in electron diffraction, so I made my own instruments in the student machine shop and studied surface chemistry. Those studies broke new ground and were quite rewarding. Still, when a very bright student, Russell Bonham (Fig. 6), a fellow who perpetually bubbled over with ideas, was assigned to my research group (yes, at Iowa State students were assigned by a committee, then), I could no more interest him in surface chemistry than Pauling had been able to interest Brockway in X-ray crystallography. Taking a page from Pauling, I asked Russ if he might be interested in studying structures of molecules by diffracting electron waves. This did catch his interest. So I made an arrangement with the University of Michigan to use the diffraction unit I had constructed as a student. I got some funds to carry out the work by applying for a grant from the American Petroleum Institute. To get started with substances I could afford, substances that were relevant to petroleum, I chose a series of n-hydrocarbons and isobutene. This may sound pretty pedestrian - it did even to me at the time- - but this series turned out to be extremely revealing. The molecule that yielded the most provocative hints about how molecules decided to direct their bonds, was isobutene [16]. As most readers will know, what can be deduced directly by electron diffraction is the spectrum of internuclear distances (via the radial distribution curve). If distances, which are broadened by molecular vibrations, are very well resolved from each other, a circumstance that is not so very common as mentioned above, structures can be deduced quite readily. But isobutene was a great disappointment. The three carbon-carbon nonbonded distances (Fig. 7) overlapped so severely that the $\mathrm{H}_{3} \mathrm{C}-\mathrm{C}-\mathrm{CH}_{3}$ bond angle could not be determined with any confidence. As far as could be told, the three carbon atoms surrounding the central carbon were distributed in an equilateral triangle. I thought that nature played a dirty trick on us, frustrating the derivation of the structure as precisely as would have been possible if only the nonbonded distances had been resolved, even just a little bit. After brooding about this unfortunate situation for some time, it suddenly stuck me that maybe nature was trying to tell us something, after all. Perhaps bond angles were not determined by hybridization (the theory in vogue at the time which made the bond angles $120^{\circ}$ in an "sp 2 " case such as isobutene). An equilateral arrangement would make the bond angle between the methyl single 


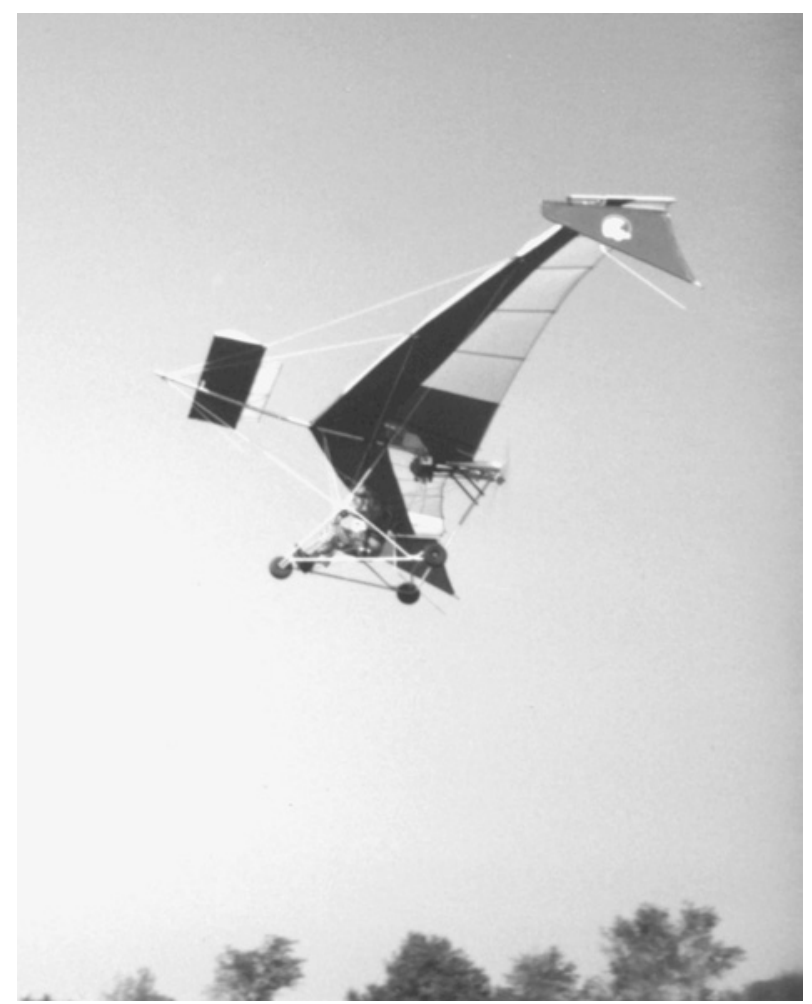

Fig. 4. The author in 1982, enjoying a flight in his ultralight aircraft which he taught himself to fly.

bonds closer to $114^{\circ}$. Perhaps, instead, bond angles are determined by the close packing of the carbon atoms around the central carbon! Exploring this lead and examining literature accounts of the structures of many molecules, it seemed clear that, for a great many small molecules, values of bond angles were established by minimizing the stress connected with geminal nonbonded repulsions [17]. One exception was ethylene, whose $\mathrm{H}-\mathrm{C}-\mathrm{H}$ angles had been determined by high resolution infrared spectroscopy to be almost exactly $120^{\circ}$. It was this result which had reinforced the notions of those championing the hybridization "theory." So Russ and I redetermined the structure of ethylene and found the published structure to be wrong [18]. Ethylene now fit our picture of "ligand-close packing," (a designation introduced later by Ronald Gillespie [19] to describe the idea). The effect of nonbonded interactions also played a significant role in bond lengths (as is also suggested in Fig. 7). Even though I was told by theorists at the time that such minor interactions as geminal nonbonded interactions would hardly compete with effects of hybridization, it was obvious to me that the hybridization theory was a fraud. Not only structures but also spectroscopy, via modified experimental Urey-Bradley force fields, supported my argument.

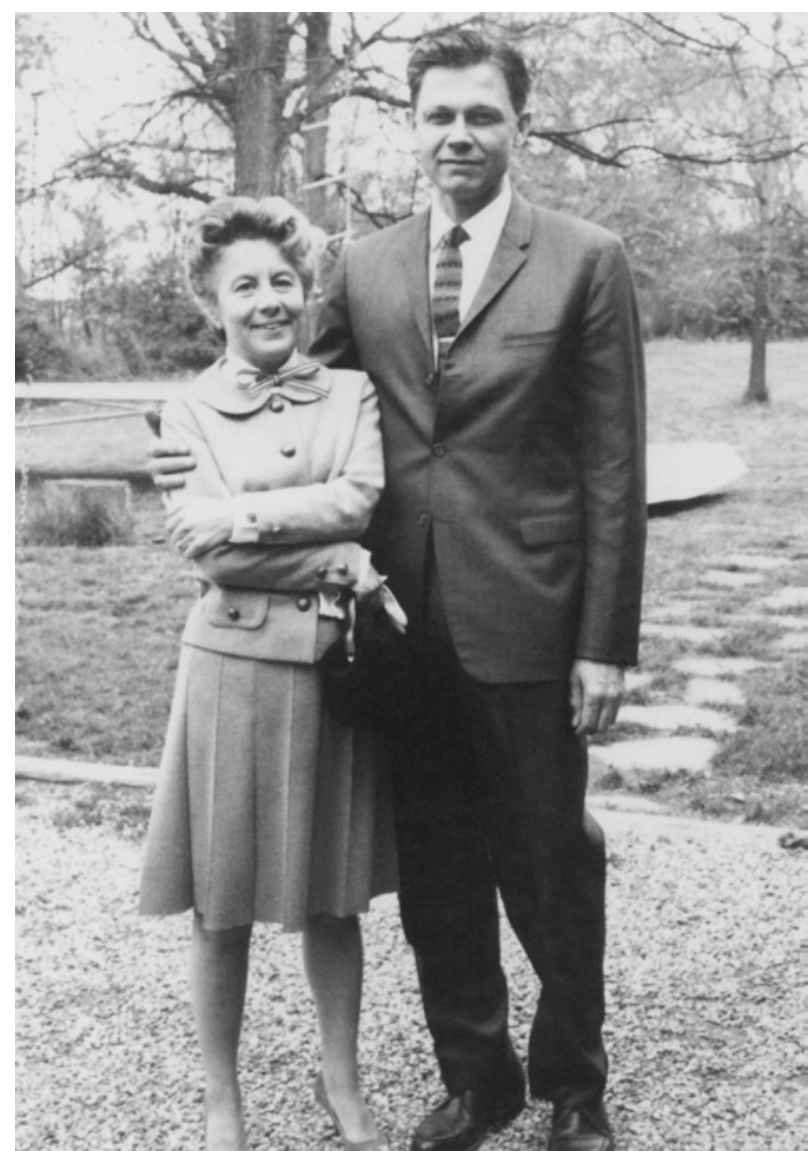

Fig. 5. The author and his wife, Joy, on Mother's Day, 1968.

Recently, Ron Gillespie and his colleagues have verified beyond doubt in extensive studies of a large variety of structures that "ligand close-packing" is indeed a dominating factor dictating bond angles and shaping bond lengths [19]. This is especially curious because when Ron and Istvan Hargittai were collaborating in the writing of a book The VSEPR Model of Molecular Geometry [20], Istvan tried without success to draw Ron's attention to the virtues of the ligand-close-packing model. It took the later independent rediscovery of the model by Gillespie, when he surveyed many structures, for him to recognize the power of the concept.

\section{INTERPRETATION OF MOLECULAR TRENDS AND ISOTOPE EFFECTS}

Instead of pursuing the ligand close-packing model as assiduously as Gillespie later did, I thought there was an even better way of handling the problem of geminal 


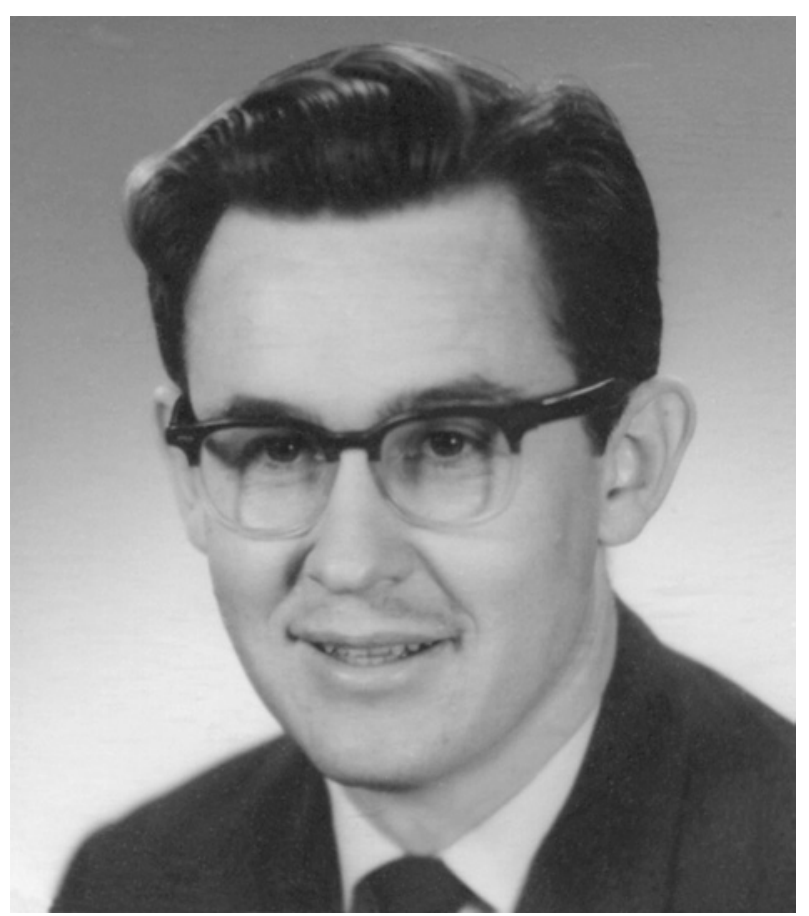

Fig. 6. Russell Bonham after he joined the faculty of the University of Indiana.

nonbonded interactions. The ligand close-packing model assigned packing radii to the atoms surrounding a central atom, a quite successful simplification but one implying that atoms are virtually hard spheres. What would be better would be to let atoms be somewhat soft. That is, to construct a transferable model force field, a modified Urey-Bradley field, and to generate structures by mini-
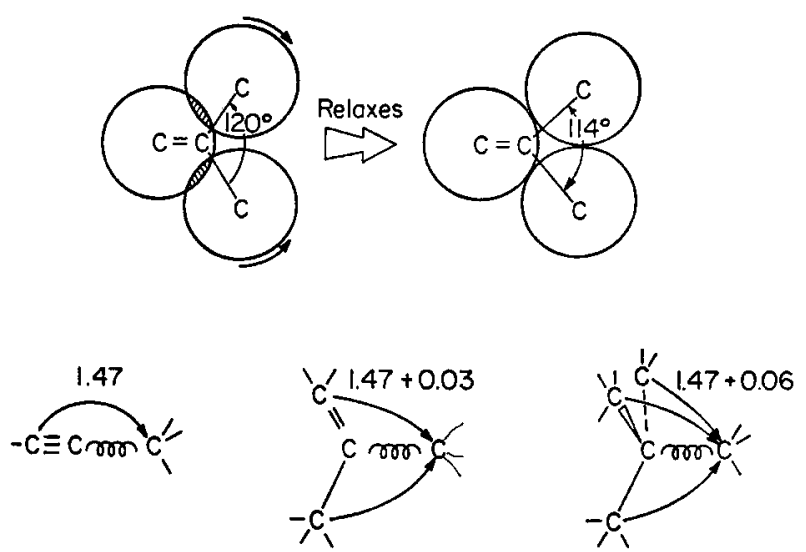

Fig. 7. Structures of hydrocarbons illustrating effects nicely accounted for by the geminal nonbonded repulsion model. The bond lengths listed apply to the bonds indicated by the springs. mizing the potential energy. The method of minimizing intramolecular potential energies soon became known as "molecular mechanics," a name I always thought was a misnomer. With Brad Thompson and Jean Jacob doing the hard work, we developed a computer program incorporating realistic laws of nonbonded interactions (which are essentially anharmonic in nature) and invoked anharmonic bond stretches [21]. Our program was a very early application of molecular mechanics and, while not the first, it was the first based on a fairly extensive experience with intramolecular force fields, an experience not possessed by the organic chemists who had initiated the method.

Our variant of molecular mechanics rewarded us by reproducing various structural trends in hydrocarbon molecules remarkably well. This was particularly true in the case of the extremely crowded molecule tri- $t$-butyl methane, a molecule that Hans-Beat Bürgi had determined the gas-phase structure of in a heroic effort with only a few milligrams of the precious material [22]. By that time, many others, including molecular physicists, had entered the field of molecular mechanics. Because it captured the essence of the physical forces more directly than expansions involving force constants, our modified UreyBradley model force field reproduced structural features of hydrocarbon molecules, including those of tri-t-butyl methane, more faithfully per parameter invoked in the force field than any of the other programs up to and well beyond that time.

After I had been at Iowa State for a few years, the politics that had initially frozen me out of the Ames Laboratory at Iowa State University had been resolved. This laboratory was equipped with lavish facilities and excellent machine shops, and I was given the opportunity to construct an electron diffraction unit. This one ultimately turned out to be far superior to the one I had made as a student at Michigan. At first, however, its performance was troublesome. Just as I put together the final pieces I got from the machine shop I was joined by my first postdoctoral scholar, Kozo Kuchitsu (Fig. 8), a fresh new PhD from Morino's group in Tokyo. That I, a green, unproven young man, was able to continue in structural chemistry with such a remarkable young scientist—one who developed into a world-class scholar-was another lucky accident. Professor Morino had intended Kozo to become seasoned by studying with Brockway, the most famous person in the electron-diffraction field. Morino intended to groom Kuchitsu to be his replacement. But Brockway happened not to have the funds to support Kuchitsu so he recommended that Kozo work with me.

One of the first things I asked Kozo to do was to test the performance of the new diffraction unit. What he 


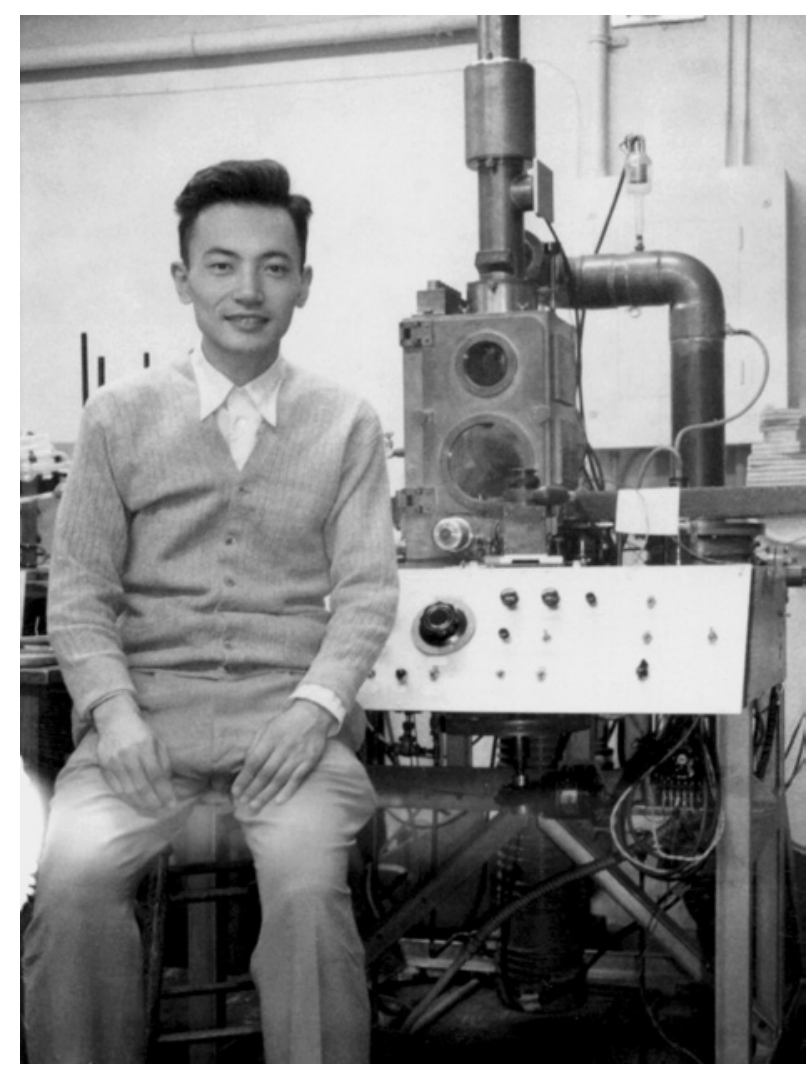

Fig. 8. Kozo Kuchitsu as a new postdoctoral scholar, posing with the new Iowa State electron diffraction unit. He later succeeded his mentor at the University of Tokyo.

found was very disturbing. Diffraction plates were badly corrupted by some sort of radiation that substantially impaired the quality of diffraction patterns. Kozo almost despaired of being able to carry out top-notch diffraction research on the diffraction unit he found himself saddled with. I had never noticed such a problem when I was a student but, then, I had scrupulously tested and refined the unit before I began to record actual diffraction patterns with it. After much work we found that the trouble was due to radiation produced from the impact of electrons on the beam trap scattering upwards away from the trap and generating further radiation that was scattered downwards to the photographic plates. We were able to correct the problem by redesigning the beam trap and by coating every part involved in the spurious scattering by an element with a low atomic number, carbon.

One of the first projects Kozo and I undertook with our new, cleaned up, unit was to investigate the effects of anharmonic vibrations. In collaboration with a new student, Robert de Neui, we initiated a study of isotope effects. Structures of methane and perdeuteromethane were determined [23]. Bonds in these molecules, to the light $\mathrm{H}$ or $\mathrm{D}$ atoms, were so stiff that, even at room temperature, the molecules were in essentially their zero-point vibrational state. Not only did $\mathrm{CH}_{4}$ exhibit larger amplitudes of vibrations than $\mathrm{CD}_{4}$, but the $\mathrm{C}-\mathrm{H}$ bonds were measurably longer than the $\mathrm{C}-\mathrm{D}$ bonds. This, of course, was to be expected for anharmonic oscillators, and the anharmonic corrections to diffraction theory were quite necessary to apply in the structure analyses. So methane exhibited primary isotope effects. Kozo carried out very nice quantum perturbation analyses [24] based on our model force field to verify that our experimental methane and perdeuteromethane structures, corrected for effects of vibration, converged to the same equilibrium structure, the hypothetical structure a molecule would have in the absence of vibrations (absence even of zero-point vibrations), i.e., the structure a molecule would have at the minimum of its potential energy function. Here it might be noted that the difference between the average $\mathrm{C}-\mathrm{H}$ bond length we saw directly and the equilibrium length was rather large, at over $0.02 \AA$. Buoyed by our success in measuring and accounting for isotope effects, my group undertook further studies of isotopic pairs.

My theory of force fields suggested that not only primary but also secondary isotope effects might be observable in structures. As an example, it would be expected that in ethane the hydrogen atoms bonded to carbon $\mathrm{C}_{1}$ would impose geminal nonbonded repulsions on $\mathrm{C}_{2}$, and vice versa, tending to stretch the $\mathrm{C}-\mathrm{C}$ bond. Moreover, because the amplitudes of hydrogen vibrations are larger than those of deuterium atoms and therefore hydrogens would exert stronger repulsions on the geminal carbons. Consequently, one might expect the mean $\mathrm{C}-\mathrm{C}$ bond in $\mathrm{C}_{2} \mathrm{H}_{6}$ to be slightly longer than that in $\mathrm{C}_{2} \mathrm{D}_{6}$. Such a phenomenon would be a secondary isotope effect because the effect would be on a bond not containing the isotopes involved. Harlan Higginbottom determined the structures and confirmed the secondary effect [25]. Later we corroborated the effect by $a b$ initio quantum computations, verifying that it indeed existed and was, as proposed, due to the larger amplitudes of vibration coupled with anharmonic terms in the force field of ethane [26]. As it developed, our experiences in publishing experimentally determined effects of anharmonicity on diffraction patterns were much more pleasant than my initial experience when I tried to publish the theoretical effects.

Of course, trouble erupted after our study of methane, the simplest of the n-hydrocarbons. The ab initio theorists reported that our equilibrium structure was badly off, according to their calculations, and methane was far too simple a molecule for quantum chemical computations to be mistaken. Theorists are seldom over-modest in their 

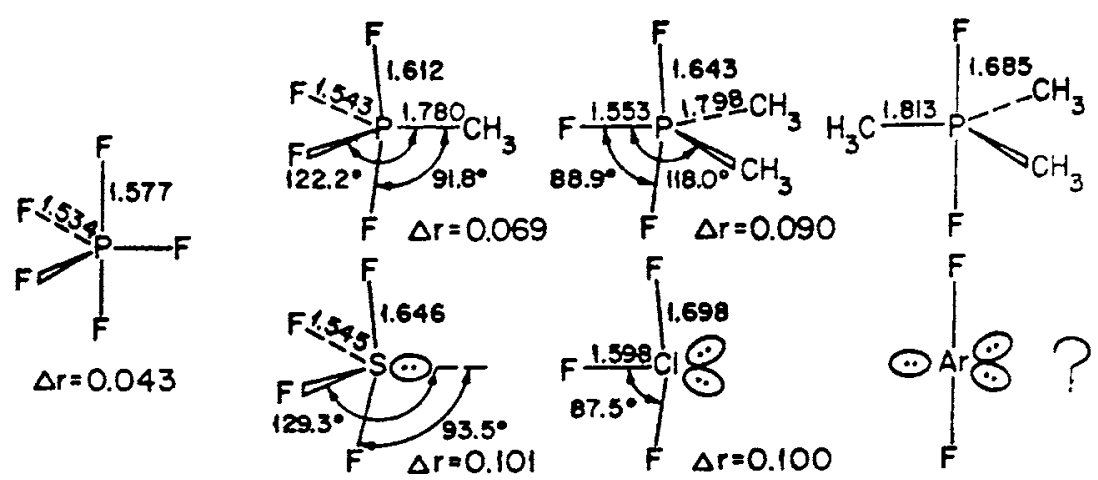

Fig. 9. Stereochemistry and structural deformations accounted for by the VSEPR model. The fluorophosphorane structures were determined by electron diffraction. The sulfur and chlorine analogs were determined by microwave spectroscopy. Although the argon compound is unknown, the illustrated structure is the structure determined for its analog, $\mathrm{XeF}_{2}$.

opinions about their prowess. Well, the quantum chemistry of the time was mistaken and it took four decades before quantum computations were sufficiently refined [27] to converge to our results.

\section{ENTANGLEMENT WITH THE VSEPR MODEL}

While we were studying ligand close-packing, the model Ron Gillespie was vigorously promoting at the time was his Valence Shell Electron Pair Repulsion (VSEPR) model [20]. Then Katy Wirth Hansen in my group carried out an absolutely beautiful study of a series of fluorophosphoranes [28]. Her results accorded so perfectly with the VSEPR model that Gillespie later used one of our figures (Fig. 9) in his lectures. But we had been ignorant of his model when Katy did her work, so we rationalized her results in terms of a simple Hückel MO model, and ignored the VSEPR model. This didn't please Gillespie one bit because his model seemed much simpler and was impressively successful. Some time after that, Gillespie and I essentially traded research programs. Structures were chosen in my research program to investigate VSEPR candidates and our results supported and augmented Gillespie's model. And, much later, Gillespie's program switched over to and greatly augmented my ligand close-packing model.

After Katy's work, the next VSEPR case we studied was the very strange molecule $\mathrm{XeF}_{6}[29,30]$, a study that came about as the result of a chance encounter with a colleague associated with the substance. This work was followed by analyses of $\mathrm{IF}_{7}$ [31] and other structures accounted for by the VSEPR model. These included the fickle and highly explosive substance $\mathrm{NCl}_{3}$ that Don Stedman was brave enough to obtain electron diffraction patterns of [32]. What we discovered that was new was that the VSEPR model, in its quantitative repelling Points-on-a-Sphere (POS) representation, gave a powerfully predictive model of intramolecular force fields that had not been appreciated by its original proponents, Gillespie and Nyholm. The idea was that if the VSEPR model provided a correct basis for understanding structure, it followed that it should also provide significant information about force fields. One useful aspect of the POS model turned out to be the correction of assignments of vibrational frequencies. The POS model reproduced with surprising accuracy the bending force constants in a variety of molecular types $[33,34]$. These constants included not only the quadratic but also cubic, and higher-order terms. Ironically, spectroscopy was blind to some aspects of the force field that could be recognized by electron diffraction in studies of extremely hot molecules. By a remarkable technique we stumbled upon by accident, Steve Goates was able to heat molecules up to $2000 \mathrm{~K}$ in a microsecond, too short a time for them to decompose but long enough for Steve to capture their diffraction patterns while they were still intact [35]. Inferences we made from the diffraction patterns about their potential energies in their wildly oscillating states were verified by quantum computations. How could the temperatures be inferred? The thermometers were in the molecules, themselves. Their amplitudes of vibration betrayed their temperatures. In a related study of molecules pumped by an infrared laser, Mike Kacner determined the number of quanta absorbed by careful measurements of the vibrational amplitudes [36]. He could also see the molecules expand, swelling up more the greater the number of quanta they consumed.

To those familiar with the VSEPR model, a model taught almost universally in elementary courses of chemistry, it must be obvious that the VSEPR and ligandclose-packing models imply almost the same sorts 
of consequences. The successful repelling Points-ona-Sphere construction could be interpreted either way. Gillespie, himself, wrote that he considered the ligandclose-packing model to be a quantitative representation of the VSEPR model. Yet, we found there is a distinction. There can no longer be a doubt that geminal nonbonded repulsions often play a large role in governing bond angles and bond lengths. Nevertheless, we found that molecular orbital computations constructed to be totally devoid of nonbonded interactions, still implied VSEPR trends in geometries and deformations.

\section{EVOLUTION AWAY FROM MOLECULAR STRUCTURE}

After exploring a wide variety of molecular structures under diverse sets of conditions, our diffraction program evolved into studies of liquid structure in samples of submicroscopic droplets generated by condensation of vapor in supersonic flow. After all, liquids were the least understood of the common states of matter, and electron diffraction offered certain advantages over X-ray and neutron diffraction in their study. This led directly to the investigation of nucleation when we discovered that some of our liquid droplets froze spontaneously while we watched them. I'll mention just one result, the freezing of submicroscopic drops of water [37]. Our technique allowed us to attain a much higher degree of supercooling of liquid water than had ever been attained in the laboratory before and, correspondingly, an enormously higher nucleation rate. The rate was twenty orders of magnitude higher than that measured in prior experimental studies. To grasp what a factor of $10^{20}$ means, consider the 14 billion years since the big bang is supposed to have happened. Compare that with $0.003 \mathrm{~s}$. The ratio between the times is 20 orders of magnitude. But this development of electron diffraction is getting too far from the subject of this volume. Therefore it is time to stop. At least the foregoing stories should make it clear that E. Bright Wilson's obituary of electron diffraction, written over a half-century ago, was premature.

\section{REFERENCES}

1. Brockway, L. O. In Fifty Years of Electron Diffraction; Goodman, P., Ed.; Reidel: Dordrecht, 1981; Part II, Chap.6.

2. Bartell, L. S. Chem. Heritage 2002, 20, 12.

3. Brockway, L. O.; Bartell, L. S. Phys. Rev. 1953, 90, 833.

4. Bartell, L. S. J. Chem. Phys. 1955, 23, 1219.

5. Bartell, L. S.; Brockway, L. O. J. Chem. Phys. 1955, 23, 1860.

6. McWhirter, N. D. (Ed.). Guinness Book of Records; Sterling: New York, 17th ed., 1979.

7. Debye, P. Ann. Physik (Leipzig) 1915, 45, 809; Debye, P. Phys. Z. 1923, 24, 161

8. Bartell, L. S.; Gavin, R. M., Jr. J. Am. Chem. Soc. 1964, 86, 3493.

9. Bauer, S. H. J. Chem. Phys. 1950, 18, 27.

10. J. Bigeleisen, J.; Mayer, M. G.; Stevenson, P. C.;Turkevich, J. J. Chem. Phys. 1948, 16, 442.

11. Schomaker, V.; Glauber, R. Nature 1952, 170, 290.

12. Jacob, E. J.; Bartell, L. S. J. Chem. Phys. 1970, 53, 2231.

13. Wong, T. C.; Bartell, L. S. J. Chem. Phys. 1973, 58, 5654.

14. Miller, B. R.; Bartell, L. S. J. Chem. Phys. 1980, 72, 800.

15. Bartell, L. S.; Brockway, L. Phys. Rev. 1953, 90, 833.

16. Bartell, L. S.; Bonham, R. A. J. Chem. Phys. 1960, 32, 824.

17. Bartell, L. S. J. Chem. Phys. 1960, 32, 827.

18. Bartell, L. S.; Bonham, R. A. J. Chem. Phys. 1959, 31, 400.

19. Gillespie, R. J. J. Chem. Educ. 1998, 75, 923.

20. Gillespie, R. J.; Hargittai, I. The VSEPR Model of Molecular Geometry; Pearson Higher Education, 1991. (City of publication unknown to me.)

21. Jacob, E. J.; Thompson, H, B.; Bartell, L. S. J. Chem. Phys. 1967, 47, 3736.

22. Bürgi, H. B.; Bartell, L. S. J. Am. Chem. Soc. 1972, 94, 5236; Bürgi, H. B.; Bartell, L. S. J. Am. Chem. Soc. 1972, 94, 5239.

23. Bartell, L. S.; Kuchitsu, K,; de Neui, R. J. J. Chem. Phys. 1961, 35, 1211.

24. Kuchitsu, K.; Bartell, L. S. J. Chem. Phys. 1962, 36, 2470.

25. Bartell, L. S.; Higginbotham, H. K. J. Chem. Phys. 1965, 42, 851.

26. Bartell, L. S., Fitzwater, S. J. J. Chem. Phys. 1977, 67, 4168.

27. Stanton, J. F. Mol. Phys. 1999, 97, 841.

28. Bartell, L. S.; Hansen, K. W. Inorg. Chem. 1965, 4, 1775, 1777.

29. Gavin, R. M. Jr.; Thompson, H. B.; Bartell, L. S.; Chernick, C. L. J. Chem. Phys. 1965, 43, 2547.

30. Bartell, L. S.; Gavin, R. M., Jr. J. Chem. Phys. 1968, 48, 2460.

31. Bartell, L. S.; Adams, W, J.; Thompson, H. B. J. Chem. Phys. 1970, $53,4040$.

32. Bürgi, H. B.; Stedman, D.; Bartell, L. S. J. Mol. Struct. 1971, 10, 31.

33. Bartell, L. S.; Plato, V. J. Am. Chem. Soc. 1973, 95, 3097.

34. Bartell. L. S. Croatica Chem, Acta 1984, 57, 927.

35. Goates, S. R.; Bartell, L. S. J. Chem. Phys. 1982, 77, 1874

36. Bartell, L. S.; Kacner, M. A. J. Chem. Phys. 1984, 81, 280.

37. Huang, J.; Bartell, L. S. J. Phys. Chem. 1995, 99, 3924. 